\title{
Effects of Disulfiram on Positron Emission Tomography and Neuropsychological Studies in Severe Chronic Alcoholism
}

\author{
Sid Gilman, Kenneth M. Adams, Doug Johnson-Greene, Robert A. Koeppe, Larry Junck, Karen J. Kluin, Susan Martorello, \\ Mary Heumann, and Elizabeth Hill
}

\begin{abstract}
Disulfiram is an aldehyde dehydrogenase inhibitor that is widely used as an adjunctive agent in the treatment of patients with severe chronic alcoholism. Recent positron emission tomography (PET) studies of local cerebral metabolic rates for glucose (ICMRglc) and benzodiazepine receptor binding in alcoholic patients have shown regional cerebral abnormalities; however, some of the patients were studied while receiving disulfiram, which could influence the biochemical processes under investigation. In a retrospective investigation, we examined the influence of disulfiram administration on the results of PET studies of ICMRgIC and benzodiazepine receptor binding and neuropsychological tests of cognition and executive function in patients with severe chronic alcoholism. $\left[{ }^{18} \mathrm{~F}\right] \mathrm{Fluorodeoxyglucose}$ was used to measure ICMRglc in 48 male patients, including 11 receiving and 37 not receiving disulfiram in therapeutic doses. $\left[{ }^{11} \mathrm{C}\right.$ ]Flumazenil was used to measure benzodiazepine receptor binding in 17 male patients, including 3 receiving and 14 not receiving disulfiram. All patients studied with FMZ were also examined with fluorodeoxyglucose. PET studies of ICMRglc revealed significantly decreased global values in the patients receiving disulfiram compared with those not receiving disulfiram. PET studies of benzodiazepine receptor binding revealed decreased flumazenil influx and distribution volume in patients receiving disulfiram. The neuropsychological tests demonstrated no differences between the two groups of subjects. The findings suggest that disulfiram may influence the results of PET studies of glucose metabolism and benzodiazepine receptor binding.
\end{abstract}

Key Words: Positron Emission Tomography, Disulfiram, Alcoholism, Fluorodeoxyglucose, Flumazenil.

From the Department of Neurology (S.G., D.J.-G., L.J., K.J.K, S.M., M.H.); Division of Neuropsychology, Department of Psychiatry (K.M.A., D.J.-G.); Division of Nuclear Medicine, Department of Internal Medicine (R.A.K.); Division of Speech Pathology, Department of Physical Medicine and Rehabilitation (K.J.K.), University of Michigan; Psychology Service, Ann Arbor Veterans Affairs Medical Center (K.M.A., D.J.-G.), and University of Michigan Alcohol Research Center (S.G., K.M.A., D.J.-G., L.J., KJ.K., S.M., E.H.), Ann Arbor, Michigan.

Received for publication May 20, 1996; accepted July 30, 1996

These investigations were supported in part by National Institutes of Health grants AA 07378 (University of Michigan Alcohol Research Center) and AG 08671 (Michigan Alzheimer's Disease Research Center) and by a sharing agreement for positron emission tomography studies between the Ann Arbor Veterans Affairs Medical Center and the University of Michigan.

Reprint requests: Sid Gilman MD, Professor and Chair, Department of Neurology, University of Michigan Medical Center, 1500 E. Medical Center Dr., Ann Arbor, MI 48109-0316.

Copyright $(1996$ by The Research Society on Alcoholism.
$\mathbf{P}$ OSTMORTEM STUDIES have demonstrated that excessive and prolonged alcohol intake can lead to extensive neuronal cell loss in the cerebral cortex and cerebellum. ${ }^{1-9}$ In living patients with severe chronic alcoholism, these changes are manifested by cerebral atrophy, including focal atrophy in the frontal regions on anatomical imaging studies, ${ }^{10-15}$ decreased local cerebral metabolic rates for glucose (ICMRglc) in the medial aspects of the frontal lobes in positron emission tomography (PET) studies with $\left[{ }^{18} \mathrm{~F}\right]$ fluorodeoxyglucose $(\mathrm{FDG}),{ }^{16,17}$ generalized cerebral changes of $1 \mathrm{CMRglc}$, including alterations over time, ${ }^{18-21}$ altered cerebral metabolic responses to a benzodiazepine challenge, ${ }^{22}$ decreased density of GABA-A/benzodiazepine (GABA-A/BDZ) receptors in the medial portions of the frontal lobes in PET studies with $\left[{ }^{11} \mathrm{C}\right]$ flumazenil (FMZ), ${ }^{23}$ and decreased performance on neuropsychological tests, particularly those reflecting frontal lobe function. ${ }^{24-27}$

Disulfiram (tetraethylthiuram disulfide) is an aldehyde dehydrogenase inhibitor that interferes with the metabolic degradation of acetaldehyde, which is produced in the first step of the oxidation of ethanol. ${ }^{28-32}$ The resulting increase in the plasma level of acetaldehyde after ethanol ingestion causes highly unpleasant symptoms, including flushing of the skin with a sensation of warmth, hypotension, tachycardia, tachypnea, palpitations, anxiety, headache, nausea, and vomiting. ${ }^{32,33}$ Disulfiram has been used extensively in the treatment of alcoholic subjects since its introduction. ${ }^{28,29}$ The metabolic products of disulfiram include a bis(diethyldithiocarbamate) copper complex, which is formed in the gastrointestinal tract and absorbed into the blood along with the parent drug; diethyldithiocarbamic acid (DDC), which is degraded to form diethylamine and carbon disulfide; diethyldithiomethylcarbamate (Me-DDC) and the glucuronic acid of DDC; diethylthiomethylcarbamate (MeDTC); and the sulfoxide and sulfone metabolites of MeDTC. ${ }^{32,34-46}$ The active agents responsible for aldehyde dehydrogenase inhibition after ingestion of disulfiram appear to be Me-DTC and its sulfoxide and sulfone metabolites. ${ }^{45-49}$ Disulfiram and its metabolites are distributed throughout the body in multiple tissues, including small amounts in the brain. ${ }^{34,50-52}$ Disulfiram and its metabolites are excreted through the gastrointestinal tract, kidney, and lungs. ${ }^{29,50,53,54}$ Many pharmaceutical agents, particularly 
those with known oxidative metabolism, interact with disulfiram, ${ }^{55,56}$ and this finding leads to the concern that disulfiram may influence the results of PET studies of ICMRglc. Disulfiram also interacts with benzodiazepines, ${ }^{57}$ raising the possibility that the drug may also affect PET studies of GABA-A/BDZ receptors.

Recently, we have utilized PET and neuropsychological evaluation to study patients with severe chronic alcoholism, including a large group examined with FDG and a smaller group with FMZ. ${ }^{17,23-25}$ These studies included a small cohort of patients taking disulfiram, providing an opportunity to determine retrospectively whether this medication alters brain function as reflected in PET measurements of $1 C M R g l c$ and GABA-A/BDZ receptor density and in neuropsychological investigations.

\section{METHODS}

\section{Patient Groups and Normal Subjects}

The studies were approved by the Institutional Review Boards of the University of Michigan Hospitals and the Ann Arbor Veterans Affairs Medical Center (AAVAMC), and informed consent was obtained from all patients. We studied 48 male chronically alcohol-dependent patients recruited predominantly from the Alcohol Treatment Program of the AAVAMC, including 11 receiving disulfiram in a dose of $250 \mathrm{mg} /$ day and 37 not receiving disulfiram at the time of study (Table 1). Lifetime alcohol use was assessed with the Lifetime Drinking Patterns History, adapted from Skinner and Sheu. ${ }^{58}$ This instrument utilizes gender, age, and alcohol consumption, permitting evaluation of patterns of alcohol consumption across multiple time lines across the life span. Data on quantity and frequency of alcohol use and on withdrawal from alcohol were recorded during interviews, and changes in patterns were analyzed. This method has been shown to produce reliable estimates of lifetime drinking. We also applied the criterion of sustained alcohol consumption exceeding $560 \mathrm{~g}$ of ethanol weekly as a second major means of benchmarking the length of the patients' histories of "heavy drinking." Comparisons of our data against other studies of alcóholic subjects confirm the status of this group as severe and chronic alcoholic patients. ${ }^{59}$ All patients met the DSM-IV ${ }^{60}$ diagnostic criteria for alcohol dependence, and all except one exceeded a weekly intake of $560 \mathrm{~g}$ of ethanol over 2 of the 3 preceding years. The one patient who was an exception had been abstinent for 5 years. All patients had been hospitalized at least once for alcoholism, and most patients previously achieved sobriety for no more than a few months before beginning the chronic use of alcohol until the current period of abstinence. These patients are characterized as "heavy" drinkers by existing epidemiological data, both in duration and intensity of alcohol intake. ${ }^{59}$ Patients were excluded if they had any history of polydrug abuse as defined by the quantitative criteria of the National Institute on Drug Abuse in its National Collaborative Study of Polydrug Abuse. ${ }^{61}$ Other exclusion criteria were severe liver disease, severe concurrent psychopathology, and neurological disorders apart from those due to alcohol, including stroke, birth complications, learning disorders, or other acquired or developmental disorders carrying neurological or neuropsychological risk. Patients with closed head injury with loss of consciousness exceeding 30 minutes were also excluded. We recorded the types and doses of all medications administered at the time of study, including disulfiram.

All patients provided a complete medical and neurological history and received a physical and neurological examination. The patients were examined in the absence of medications that could influence cognition, the motor system, or the PET studies. Benzodiazepines that had been administered to reduce withdrawal symptoms were discontinued at least 6 weeks before PET scans in all cases except one, in whom chlordiazepoxide was discontinued 13 days before the study. The patients were studied with PET after they had achieved at least 30 days of sobriety except for one, in whom the PET study was conducted after 17 days of abstinence. At the time of study, the patients were consuming a nutritious diet and had no evidence of ketosis, as determined by urinalysis. We ensured that the patients had achieved sobriety as described by recruiting the patients from an alcohol treatment program involving admission to an inpatient facility that has a 21-day program emphasizing experiential treatment activities. After discharge, the patients were followed in an intensive outpatient program requiring regular appointments for medical follow-up and group therapy. These patients were monitored closely and directly by caregivers experienced in the treatment of alcoholism. The principal focus of the outpatient treatment program in the postacute phase was relapse prevention. In addition, these patients were observed by one of the investigators just before their PET scans, and they were questioned concerning compliance with the prescan requirements concerning food and liquid intake, including alcohol consumption. This observation provided an opportunity to detect signs of drinking.

The patients were divided into two groups based upon use of disulfiram as an adjunct to their treatment program. The patients in both groups had similar clinical and demographic characteristics, because applicants for admission to the Ann Arbor Veterans Affairs Medical Center must qualify for treatment on the basis of both military service history and screens for level of income. These requirements usually limit admissions to patients in the lower middle class or lower class. Almost all of the patients in this study were white, most were in older middle age (Table 1), and all had served in the armed forces in enlisted status. We found no characteristics that differentiated the groups from either a demographic or a clinical perspective. The subjects in both groups had histories of chronic alcoholism that had not been treated successfully. Each of the patients had at least one previous inpatient admission for intensive alcohol treatment. As indicated above, at the time of study the patients had been detoxified, leaving only effects that result from the chronic and not the acute effects of alcohol.

\section{Positron Emission Tomography}

These studies were standardized for all subjects. The subjects fasted for $4 \mathrm{hr}$ before the scan and were studied lying supine and awake in a quiet room, alert but not speaking, with eyes open from 5 minutes before injection until completion of the scan. A catheter was placed in a radial artery for blood sampling. PET studies of ICMRglc were performed after intravenous injection of $10 \pm 1 \mathrm{mCi}$ of FDG. In the 17 patients also examined with $F M Z, 22 \pm 2 \mathrm{mCi}$ of this agent were given first for the GABA-A/BDZ studies and followed 90 minutes later by $10 \mathrm{mCi}$ of FDG for the ICMRglc studies.

The subjects were imaged with either a Siemens/CTI 931/08-12 or a Siemens ECAT EXACT-47 scanner. Images from both scanners were reconstructed to a resolution of 8-9 $\mathrm{mm}$ full-width at half-maximum (FWHM) in-plane. Because the axial sampling of the EXACT-47 scanner is twice as fine as the 931, two adjacent levels from the EXACT were averaged, providing images with the same axial spacing and nearly the same axial resolution as the 931 scanner. Attenuation correction was calculated by the standard ellipse method.

In the FDG studies, data were acquired from 30 to $90 \mathrm{~min}$ after injection and quantified with the static scan method of Hutchins et al. ${ }^{62}$ For the FMZ studies, flumazenil was labeled with carbon-11 at high specific radioactivity using a methylation process. ${ }^{63} \mathrm{~A}$ dynamic sequence of 15 scans was acquired for $60 \mathrm{~min}$ after tracer administration. Blood samples were taken as rapidly as possible during the first $2 \mathrm{~min}$ after tracer injection and then at progressively longer intervals throughout the remainder of the study. We took a total of 25-30 samples per scan. The samples were centrifuged, and the plasma radioisotope concentrations were measured in a NaI well counter. Plasma levels of radiolabeled metabolites of FMZ were determined by a rapid Sep-Pak $\mathrm{C}_{18}$ cartridge chromatographic technique ${ }^{64}$ in the samples taken at $1 \mathrm{~min}, 2 \mathrm{~min}$, and every sample from 3 min until the end of the scan. Radioactive fiducials with $1 \mu \mathrm{Ci}$ of $\left[{ }^{18} \mathrm{~F}\right] \mathrm{FDG}$ were placed on each subject's scalp. In studies utilizing both 
FDG and FMZ in the same subject, radioactive fiducials with $5 \mu \mathrm{Ci}$ of $\left[{ }^{11} \mathrm{C}\right] \mathrm{FMZ}$ were placed initially, then relabeled with $1 \mu \mathrm{Ci}$ of $\left[{ }^{18} \mathrm{~F}\right] \mathrm{FDG}$ before the 1CMRglc scan without removing them. Computer routines automatically determined the locations of these fiducials and used this information to correct for patient motion. The PET studies were analyzed with a compartmental model and parameter estimation technique that provides pixel-by-pixel determinations of each measurement, thus creating "functional" images. ${ }^{65}$ The studies with FMZ provided quantitative measurement of ligand influx $\left(K_{1}\right)$, which is highly correlated with flow because the single-pass extraction fraction for flumazenil is greater than $50 \% .^{66}$ The studies also provided measurement of FMZ distribution volume (DV), which is linearly related to the density of available receptor sites divided by the ligand dissociation constant $\left(B_{\max }{ }^{\prime} / K_{\mathrm{D}}\right)$. The methods for benzodiazepine receptor binding measurement, including the assumptions and limitations and the performance of $\left[{ }^{11} \mathrm{C}\right]$ flumazenil, are published. ${ }^{64-66}$

\section{PET Data Analysis}

PET images were transformed into a standard stereotactic orientation utilizing an automated method for registration into the coordinate system defined by the Talairach atlas ${ }^{67}$ followed by linear scaling and nonlinear warping. ${ }^{68}$ After anatomic standardization, stereotactically defined volumes-of-interest (VOIs) were placed on all subjects for each group. Comparisons then were made between groups. For studies with $\left[{ }^{18} \mathrm{~F}\right] \mathrm{flu}$ orodeoxyglucose, we obtained VOIs bilaterally in regions known from previous studies to show (a) significantly low ICMRglc values in severe chronic alcoholism (medial frontal region); ${ }^{16,17}$ (b) correlations between ICMRglc and performance on neuropsychological tests of executive function in severe chronic alcoholism (dorsolateral and orbitomedial frontal cortex); ${ }^{24,25}$ and (c) no abnormalities and no correlation with neuropsychological test performance in severe chronic alcoholism (posterior superior temporal region, inferior parietal region, and cerebellar hemispheres). Global measures of ICMRglc were also compared between groups to determine whether disulfiram might affect the entire brain to the same degree as individual regions. The same VOIs were examined in the studies with $\left[{ }^{11} \mathrm{C}\right]$ flumazenil for comparison with the ICMRglc data and because abnormalities of benzodiazepine receptor binding have been found in the medial portion of the frontal cortex. ${ }^{23}$

\section{Structural Imaging}

We obtained magnetic resonance (MR) images utilizing 1.5T scanners. The scans were reviewed with a neuroradiologist.

\section{Neuropsychological Testing}

All patients received a neuropsychological evaluation by a clinical neuropsychologist in a well lighted room free of interruptions and distractions. The neuropsychological battery consisted of a modified and expanded Halstead-Reitan Neuropsychological Test Battery (HRNTB), which included several tests of general cognitive function as well as the Category Test, a test of executive cognitive skills the results of which have been found previously to be abnormal in alcoholic subjects. The neuropsychological tests used in this investigation have established reliability and validity and are widely used in neuropsychological laboratories. ${ }^{69}$

\section{Statistical Analyses}

Patients in the two groups were compared with univariate tests ( $t$ tests with unequal variance). Clinical and demographic characteristics were compared to determine whether groups were comparable on variables that might confound neuropsychological and PET comparisons. Data obtained from PET studies with FDG in the two groups were compared focusing upon regions described above. Data obtained from PET studies with FMZ were compared in the same structures as the FDG studies by examining the percent differences between groups. The data were examined without attempts at statistical comparison because of the small number of cases in
Table 1. Patient Groups

\begin{tabular}{lcl}
\hline \multicolumn{1}{c}{ Measure } & $\begin{array}{c}\text { No disulfiram } \\
(n=37)\end{array}$ & $\begin{array}{c}\text { Disulfiram } \\
(n=11)\end{array}$ \\
\hline Age (years) & $48 \pm 9$ & $48 \pm 7$ \\
Education (years) & $13 \pm 2$ & $13 \pm 2$ \\
Lifetime alcohol consumption & $101 \pm 65$ & $84 \pm 52$ \\
Years of heavy drinkingt & $20 \pm 10$ & $21 \pm 7$ \\
\hline
\end{tabular}

Data are presented as mean \pm standard deviation. None of the comparisons are significant.

- Estimated number of lifetime drink equivalents (two ounce 80-proof alcohol units) in thousands.

† Number of years patients consumed an average of 560 grams of ethanol weekly.

Table 2. Local Cerebral Metabolic Rates for Glucose (in $\mathrm{mg} / 100 \mathrm{~g} / \mathrm{min}$ ) Displayed as Mean \pm Standard Deviation in Two Groups of Severe Chronic Alcoholic Patients and Percent Decrease in the Group Receiving Disulfiram

\begin{tabular}{lccc}
\hline \multicolumn{1}{c}{ Structure } & $\begin{array}{c}\text { No disulfiram } \\
(n=37)\end{array}$ & $\begin{array}{c}\text { Disulfiram } \\
(n=11)\end{array}$ & $\begin{array}{c}\text { Percent } \\
\text { decrease }\end{array}$ \\
\hline Medial frontal & $6.5 \pm 1.0$ & $5.7 \pm 0.7^{*}$ & 12 \\
Dorsolateral frontal & $6.7 \pm 0.9$ & $5.9 \pm 0.6^{*}$ & 12 \\
Orbitomedial frontal & $5.7 \pm 0.7$ & $5.0 \pm 0.5^{*}$ & 12 \\
Posterior superior temporal & $7.0 \pm 0.9$ & $6.3 \pm 0.7^{*}$ & 10 \\
Inferior parietal & $6.7 \pm 1.0$ & $6.0 \pm 0.7 \dagger$ & 10 \\
Cerebellar hemispheres & $5.2 \pm 0.7$ & $4.7 \pm 0.4^{*}$ & 10 \\
Global & $5.1 \pm 0.7$ & $4.5 \pm 0.5^{*}$ & 12 \\
\hline
\end{tabular}

$* p<0.01$.

$\dagger p<0.02$.

the group receiving disulfiram $(n=3)$ compared with the group not receiving disulfiram $(n=14)$. Univariate $t$ tests were used to compare neuropsychological test performance in the two groups.

\section{RESULTS}

\section{Patient Groups}

Comparison of the 11 patients receiving disulfiram with the 37 patients not receiving disulfiram revealed no significant differences between groups in age, length of education, lifetime alcohol consumption, or years of heavy drinking (Table 1).

\section{PET Studies}

Statistical testing revealed significant differences in ICMRglc between groups for global values and for every region examined, with the group receiving disulfiram exhibiting consistently lower values than the group not receiving disulfiram (Table 2). The percent decrease in the disulfiram group was similar for global values and for all regions studied, including the medial frontal region (Table 2). Normalization of these data to the global values eliminated all significant differences between groups (Table 3 ).

FMZ kinetic data were compared between the two groups using absolute values of $K_{1}$ and DV (Table 4). The data revealed lower global and regional values in the group receiving disulfiram than in the group not receiving disulfiram. Larger percentage decreases in the disulfiram group were observed for DV than for $K_{1}$ data. After normalization, there were no regional differences in $K_{1}$ or DV. 
Table 3. Local Cerebral Metabolic Rates for Glucose Normalized to Global Values Displayed as Mean \pm Standard Deviation in Two Groups of Severe Chronic Alcoholic Patients

\begin{tabular}{lcc}
\hline \multicolumn{1}{c}{ Structure } & $\begin{array}{c}\text { No disulfiram } \\
(n=37)\end{array}$ & $\begin{array}{c}\text { Disulfiram } \\
(n=11)\end{array}$ \\
\hline Medial frontal & $1.29 \pm 0.08$ & $1.27 \pm 0.03$ \\
Dorsolateral frontal & $1.32 \pm 0.07$ & $1.32 \pm 0.05$ \\
Orbitomedial frontal & $1.13 \pm 0.07$ & $1.12 \pm 0.03$ \\
Posterior superior temporal & $1.38 \pm 0.07$ & $1.39 \pm 0.04$ \\
Inferior parietal & $1.32 \pm 0.06$ & $1.33 \pm 0.06$ \\
Cerebellar hemispheres & $1.03 \pm 0.12$ & $1.06 \pm 0.10$ \\
\hline
\end{tabular}

None of the above comparisons are significant.

\section{Neuropsychological Tests}

The patients receiving disulfiram showed no significant differences from the patients not receiving disulfiram in either measurements of general impairment or of executive function (Table 5).

\section{Structural Imaging}

Review of MR images revealed no structural abnormalities apart from atrophy in the patients and no identifiable differences between groups.

\section{DISCUSSION}

The results of this investigation utilizing PET with FDG revealed significantly lower absolute lCMRglc values in patients with severe chronic alcoholism receiving disulfiram than in a similar group of patients not receiving the medication. The two groups were comparable in age, education, lifetime alcohol consumption, and years of heavy drinking. Neuropsychological test performance was not different between the two groups. The differences in global values between groups were similar to the differences between groups in each of the regions studied, suggesting that the differences result from a general, probably metabolic, effect of disulfiram. The nature of the effect was not determined in this study; however, it seems likely to result from interactions of one or more of the multiple products of disulfiram metabolism with one or more components of the pathways of oxidative metabolism. ${ }^{32,55,56}$ The results give some concern about previous studies that showed abnormalities of ICMRglc in patients with severe chronic alcoholism, most of which did not state whether the patients examined were receiving this medication. ${ }^{16-22}$ It was reassuring to find in the present studies that the differences between the patients receiving disulfiram and those not receiving disulfiram disappeared when the data were normalized to global values, because this result indicates that the effects of disulfiram are global, with no regional specificity, and many previous studies have reported normalized rather than absolute data. Moreover, some of the previous studies demonstrated focal abnormalities in the medial frontal region and, in patients with alcoholic cerebellar degeneration, within the midline portions of the cerebellum as well. ${ }^{17}$ These focal abnormalities are unlikely to result from a global disturbance of glucose metabolism owing to effects of the medication.

The results of the investigation utilizing PET with FMZ to examine benzodiazepine receptor binding in the two groups of patients must be viewed as preliminary because the size of the group receiving disulfiram was small. Because of the small sample size, statistical testing was not attempted, but the results were generally similar to those obtained with FDG, showing decreased values in the patients receiving disulfiram. Studies of ligand influx $\left(K_{1}\right)$ revealed modest differences between groups, whereas studies of receptor binding (DV) showed much larger differences. This indicates that the differences are not due to changes in cerebral blood flow. Differences between groups in both $K_{1}$ and DV were similar in all regions examined, suggesting that the results reflect a global effect of the medication on benzodiazepine receptor binding. Here again the mechanism underlying the results was not addressed, but several metabolic products of disulfiram are capable of influencing benzodiazepine receptor binding. ${ }^{23}$

The results of this investigation raise two issues. First, as noted above, the nature of the changes in ICMRglc and in benzodiazepine receptor binding from administration of disulfiram have not been determined. This agent could affect the results by altering the biochemical processes influencing glucose metabolism and benzodiazepine receptor integrity, by influencing the measurement processes, or by both mechanisms. Although alterations of cerebral glucose metabolism and benzodiazepine receptor function from drug administration are conceivable, disulfiram has been used safely for many years, and the literature does not support the notion of major alterations in cerebral cortical function or of adverse changes in cognition from the medication. Hence, an effect on the measurement process seems more likely than an influence upon cellular metabolism and receptor function. The second issue is that the patients who received disulfiram were treated based upon the clinicians' impression of subjects who would benefit from this substance. Many clinicians prescribe disulfiram for patients at highest risk for relapse, and these are the patients who frequently have the lowest coping skills. It is conceivable that there are clinical differences between the groups studied that in turn influence the use of disulfiram, and these differences might account for the results of the PET studies, irrespective of the effects of disulfiram. This issue deserves consideration in the interpretation of the findings. Future investigations will be needed to explore the issue further.

We should emphasize that this study is retrospective and does not address the neuropsychological effects of disulfiram that might be seen in a randomized and double blind study. Nevertheless, the lack of differences in neuropsychological tests between patients receiving disulfiram and those not receiving disulfiram is consistent with available descriptions of the effects of disulfiram indicating that the medication has no adverse effects on cognition. 
Table 4. Benzodiazepine Receptor Binding Studies Showing Absolute Levels of Ligand Influx $\left(K_{1}\right)$ and Receptor Distribution Volume (DV) in Patients with Severe Chronic Alcoholism Receiving Disulfiram $(n=3)$ and Not Receiving Disulfiram $(n=14)$ and Percent Decrease (\% dec) in the Group Receiving Disulfiram

\begin{tabular}{|c|c|c|c|c|c|c|}
\hline Structure & $\begin{array}{c}K_{1} \\
\text { no disulfiram }\end{array}$ & $\begin{array}{c}K_{1} \\
\text { disulfiram }\end{array}$ & $\begin{array}{c}\% \\
\text { dec }\end{array}$ & $\begin{array}{c}\text { DV } \\
\text { no disulfiram }\end{array}$ & $\begin{array}{c}\text { DV } \\
\text { disulfiram }\end{array}$ & $\begin{array}{c}\% \\
\text { dec }\end{array}$ \\
\hline Medial frontal & $0.33 \pm 0.07$ & $0.30 \pm 0.03$ & 9 & $6.12 \pm 1.26$ & $4.78 \pm 0.30$ & 22 \\
\hline Dorsolateral frontal & $0.33 \pm 0.07$ & $0.30 \pm 0.02$ & 9 & $6.00 \pm 0.77$ & $4.79 \pm 0.22$ & 20 \\
\hline Orbitomedial frontal & $0.29 \pm 0.05$ & $0.27 \pm 0.03$ & 7 & $5.49 \pm 0.78$ & $4.82 \pm 0.39$ & 12 \\
\hline Posterior superior temporal & $0.37 \pm 0.07$ & $0.36 \pm 0.03$ & 3 & $6.72 \pm 0.91$ & $5.50 \pm 0.51$ & 18 \\
\hline Inferior parietal & $0.34 \pm 0.07$ & $0.32 \pm 0.02$ & 6 & $6.10 \pm 0.87$ & $5.06 \pm 0.32$ & 17 \\
\hline Cerebellar hemispheres & $0.32 \pm 0.05$ & $0.31 \pm 0.07$ & 3 & $4.17 \pm 0.76$ & $3.13 \pm 0.26$ & 25 \\
\hline Global & $0.27 \pm 0.05$ & $0.25 \pm 0.02$ & 7 & $4.49 \pm 0.66$ & $3.65 \pm 0.12$ & 19 \\
\hline
\end{tabular}

Table 5. Comparison of Neuropsychological Test Performance in Two Groups of Severe Chronic Alcoholic Patients

\begin{tabular}{lcc}
\hline $\begin{array}{c}\text { Neuropsychological } \\
\text { tests }\end{array}$ & $\begin{array}{c}\text { No disulfiram } \\
(n=37)\end{array}$ & $\begin{array}{c}\text { Disulfiram } \\
(n=11)\end{array}$ \\
\hline WAIS-R FS & $99 \pm 9$ & $97 \pm 13$ \\
TPT Total & $17 \pm 6$ & $18 \pm 9$ \\
H-R II & $0.5 \pm 0.2$ & $0.5 \pm 0.3$ \\
HCT & $60 \pm 26$ & $64 \pm 30$ \\
\hline
\end{tabular}

WAIS-R FS, Wechsler Adult Intelligence Scale-Revised Full Scale IQ; TPT Total, Tactual Performance Test Total Time in minutes; H-R II, Halstead-Reitan Impairment Index; HCT, Total Errors on the Halstead Category Test. None of the above comparisons are significant.

Finally, a clear implication of the findings in this study is the need for caution in interpreting the results of PET studies of glucose metabolism or ligand binding in severe chronic alcoholic patients taking disulfiram. This caution will need to be exercised with other ligands that will be used in the future as probes with PET or single photon emission computed tomographic studies.

\section{ACKNOWLEDGMENTS}

We thank the personnel of the PET Center of the Division of Nuclear Medicine for production of the PET isotopes and acquisition of the scans, and Dr. David Kuhl for assistance. We also thank Drs. Phillip Kroll and Stanley Berent and the personnel of the University of Michigan Alcohol Research Center.

\section{REFERENCES}

1. Courville CB: Effects of Alcohol in the Nervous System of Man. Los Angeles, San Lucas Press, 1955

2. Torvik A, Lindboe CF, Rogde S: Brain lesions in alcoholics: A neuropathological study with clinical correlations. J Neurol Sci 56:233248, 1982

3. Ferrer I, Fabregues I, Rairiz J, Galofre E: Decreased numbers of dendritic spines on cortical pyramidal neurons in human chronic alcoholism. Neurosci Lett 69:115-119, 1986

4. Harper CG, Kril J, Daly J: Are we drinking our neurones away? $\mathrm{Br}$ Med J 294:534-536, 1987

5. Kril J, Harper CG: Neuronal counts from four cortical regions of alcoholic brains. Acta Neuropathol 79:200-204, 1989

6. Krill JJ, Harper CG: Neuronal counts from four cortical regions of alcoholic brains. Acta Neuropathol 79:200-204, 1989

7. Harper C, Kril J: Patterns of neuronal loss in the cerebral cortex in chronic alcoholic patients. J Neurol Sci 92:81-89, 1989

8. Harper C, Corbett D: Changes in basal dendrites of cortical pyramidal cells from alcoholic patients-a quantitative Golgi study. J Neurol Neurosurg Psychiatry 53:856-861, 1990

9. Harper C, Kril J: If you drink your brain will shrink. Neuropatho- logical considerations. Alcohol Alcohol (Suppl. 1):375-380, 1991

10. Carlen PL, Wortzman G, Holgate RC, Wilkinson DA, Rankin JG: Reversible cerebral atrophy in recently abstinent chronic alcoholics measured by computerized tomography scans. Science 200:1076-1078, 1978

11. Carlen PL, Wilkinson DA, Wortzman G, Holgate R, Cordingley J, Lee MA, Huszar L, Moddel G, Singh R, Kiraly L, Rankin JG: Cerebral atrophy and functional deficits in alcoholics without clinically apparent liver disease. Neurology 31:377-385, 1981

12. Carlen PL, Penn RK, Fornazzari L, Bennett J, Wilkinson DA, Phil D, Wortzman G: Computerized tomographic scan assessment of alcoholic brain damage and its potential reversibility. Alcohol Clin Exp Res 10:226232, 1986

13. Ron MA, Acker W, Shaw GK, Lishman WA: Computerized tomography of the brain in chronic alcoholism: A survey and follow-up study. Brain 105:497-514, 1982

14. Ishii T: A comparison of cerebral atrophy in CT scan findings among alcoholic groups. Acta Psychiatr Scand (Suppl.) 309:7-30, 1983

15. Jernigan TL, Butters N, Ditraglia G, Schafer K, Smith T, Invin M, Grant I, Schuckit M, Cermayk LS: Reduced cerebral grey matter observed in alcoholics using magnetic resonance imaging. Alcohol Clin Exp Res 15:418-427, 1991

16. Samson Y, Baron J-C, Feline A, Bones J, Crouzel C: Local cerebral glucose utilisation in chronic alcoholics: A positron tomography study. J Neurol Neurosurg Psychiatry 49:1165-1170, 1986

17. Gilman S, Adams K, Koeppe RA, Berent S, Kluin KJ, Modell J, Kroll P, Brunberg JA: Cerebellar and frontal hypometabolism in alcoholic cerebellar degeneration studied with positron emission tomography. Ann Neurol 28:775-785, 1990

18. Volkow ND, Hitzemann RJ, Wang GJ, Volkow ND, Hitzemann R, Wang G-J, Fowler JS, Burr G, Pascani K, Dewey SL, Wolf AP: Decreased brain metabolism in neurologically intact healthy alcoholics. Am J Psychiatry 149:1016-1022, 1992

19. Wang GJ, Volkow ND, Hitzemann RJ, Oster ZH, Roque CT, Cestaro VL: Brain imaging of an alcoholic with MRI, SPECT and PET. Am J Physiol Imaging 7:194-198, 1992

20. Wang G-J, Volkow ND, Roque CT, Cestaro VL, Hitzemann RJ, Cantos EL, Levy AV, Dhawan AP: Functional importance of ventricular enlargement and cortical atrophy in healthy subjects and alcoholics as assessed with PET, MR imaging, and neuropsychologic testing. Radiology 186:59-65, 1993

21. Volkow ND, Wang GJ, Hitzemann RJ, Fowler JS, Overal JE, Burr G, Wolf AP: Recovery of brain glucose metabolism in detoxified alcoholics. Am J Psychiatry 151:178-183, 1994

22. Volkow ND, Wang G-J, Hitzemann R, Fowler JS, Wolf AP, Pappas N, Biegon A, Dewey SL: Decreased cerebral response to inhibitory neurotransmission in alcoholics. Am J Psychiatry 150:417-422, 1993

23. Gilman S, Koeppe RA, Adams K, Johnson-Greene D, Junck L, Kluin KJ, Brunberg J, Martorello S, Lohman M: PET studies of cerebral benzodiazepine receptor binding in chronic alcoholics. Ann Neurol 39: 241-255, 1996

24. Adams KM, Gilman S, Koeppe RA, Kluin KJ, Brunberg JA, Dede D, Berent S, Kroll PD: Neuropsychological deficits are correlated with frontal hypometabolism in positron emission tomography studies of older alcoholic patients. Alcohol Clin Exp Res 17:205-210, 1993 
25. Adams KM, Gilman S, Koeppe R, Kluin K, Junck L, Lohman M, Johnson-Greene D, Berent S, Dede D, Kroll P: Correlation of neuropsychological function with cerebral metabolic rate in subdivisions of the frontal lobes of older alcoholic patients measured with $\left[{ }^{18} \mathrm{~F}\right.$ ffluorodeoxyglucose and positron emission tomography. Neuropsychology 9:275-280, 1995

26. Grant I, Adams KM, Reed R: Intermediate-duration (subacute) organic mental disorder of alcoholism, in Grant I (ed): Neuropsychiatric Correlates of Alcoholism. Washington, DC, American Psychiatric Press, 1986

27. Pishkin V, Lovallo WR, Bourne LE: Chronic alcoholism in males: Cognitive deficit as a function of age of onset, age and duration. Alcohol Clin Exp Res 9:400-406, 1985

28. Hald J, Jacobsen E: The formation of acetaldehyde in the organism after ingestion of Antabuse (tetraethylthiuramdisulphide) and alcohol Acta Pharmacol 4:305-310, 1948

29. Hald J, Jacobsen E, Larsen V: The sensitizing effect of tetraethylthiuramdisulphide (Antabuse) to ethyl alcohol. Acta Pharmacol 4:285296,1948

30. Fujiwara I, Duwana S: Studies on the metabolism of ethyl alcohol and the effect of Antabuse. Acta Med Biol 1:379-390, 1954

31. Asmussen E, Hald J, Larsen V: The pharmacological action of acetaldehyde on the human organism. Acta Pharmacol 4:311-320, 1948

32. Johansson B: A review of the pharmacokinetics and pharmacodynamics of disulfiram and its metabolites. Acta Psychiatr Scand 86:15-26, 1992

33. Petersen EN: The pharmacology and toxicology of disulfiram and its metabolites. Acta Psychiatr Scand 86:7-13, 1992

34. Strömme JH: Distribution and chemical forms of diethyldithiocarbamate and tetraethyl disulphide (disulfiram) in mice in relation to radioprotection. Biochem Pharmacol 15:287-297, 1966

35. Johansson B: Bis-(diethyldithiocarbamate) copper complex: A new metabolite of disulfiram. Biochem Pharmacol 34:2989-2991, 1985

36. Johansson B: Distribution of disulfiram and its chief metabolites over erythrocyte membranes and inactivation of erythrocyte aldehyde dehydrogenase activity. Pharmacol Toxicol 66:104-108, 1990

37. Strömme JH: Effects of diethyldithiocarbamate and disulfiram on glucose metabolism and glutathione content of human erythrocytes. Biochem Pharmacol 12:705-715, 1963

38. Strömme JH: Interaction of disulfiram and diethyldithiocarbamate with serum proteins studied by means of a gel-tiltration technique. Biochem Pharmacol 14:381-391, 1965

39. Strömme JH: Methaemoglobin formation induced by thiols. Biochem Pharmacol 12:937-948, 1963

40. Johansson B: Rapid and sensitive on-line precolumn purification and high-performance liquid chromatographic assay for disulfiram and its metabolites. J Chromatogr 378:419-429; 1986

41. Agarwal RP, Mcpherson RA, Philips M: Rapid degradation of disulfiram by serum albumin. Res Commun Chem Pathol Pharmacol 42:293-310, 1983

42. Vallari RC, Pietruszko R: Human aldehyde dehydrogenase: Mechanism of inhibition by disulfiram. Science 216:637-639, 1982

43. Deitrich RA, Hellerman L: Diphosphopyridine nucleotide-linked aldehyde dehydrogenase. J Biol Chem 238:1683-1689, 1963

44. Cobby J, Mayersohn M, Selliah S: The rapid reduction of disulfiram in blood and plasma. J Pharmacol Exp Ther 202:724-731, 1977

45. Johansson B, Petersen EN, Arnold E: Diethylthiocarbamic acid methyl ester, a potent inhibitor of aldehyde dehydrogenase found in rats treated with disulfiram or diethyldithiocarbamic acid methyl ester. Biochem Pharmacol 38:1053-1059, 1989

46. Hart BW, Yourick JJ, Faiman MD: S-methyl-N,N-diethylthiocarbamate: A disulfiram metabolite and potent rat liver mitochondrial low $K_{m}$ aldehyde dehydrogenase inhibitor. Alcohol 7:165-169, 1990

47. Yourick JJ, Faiman MD: Comparative aspects of disulfiram and its metabolites in the disulfiram-ethanol reaction in the rat. Biochem Phar- macol 38:413-421, 1989

48. Yourick JJ, Faiman MD: Disulfiram metabolism as a requirement for the inhibition of rat liver mitochondrial low $\mathrm{Km}$ aldehyde dehydrogenase. Biochem Pharmacol 42:1361-1366, 1991

49. Petersen EN: Pharmacological effects of diethylthiocarbamic acid methyl ester, the active metabolite of disulfiram? Eur J Pharmacol 166: 419-426, 1989

50. Eldjarn L: Metabolism of tetraethylthiuramdisulphide (Antabuse, Aversan) in man, investigated by means of radioactive sulfur. Scand J Clin Lab 2:202-208, 1950

51. de Saint-Blanquat G, Vidaillac G, Lindenbaum A, Derache R: Absorption digistive, fixation tissuelaire et excretion du disulfirame administrere oralement chez le rat. Arch Int Pharmacodyn 239:339-350, 1976

52. Faiman M, Dodd D, Hanzlik R: Distribution of ${ }^{35} \mathrm{~S}$ disulfiram and metabolites in mice and metabolites of ${ }^{35} \mathrm{~S}$ disulfiram in the dog. Res Commun Chem Pathol Pharmacol 21:543-567, 1978

53. Iber FL, Dutta S, Shamszad M, Krause S: Excretion of radioactivity following the administration of 35 sulfur-labeled disulfiram in man. Alcohol Clin Exp Res 1:354-359, 1977

54. Pedersen SB: Analysis and preliminary pharmacokinetics of disulfiram. Arch Pharm Chemi Sci Ed 8:65-82, 1980

55. Banys P: The clinical use of disulfiram (Antabuse): A review. J Psychoact Drugs 20:243-259, 1988

56. Poulsen HE, Loft S, Andersen JR, Andersen M: Disulfiram therapy-adverse drug reactions and interactions. Acta Psychiatr Scand 86: 59-66, 1992

57. MacLeod SM, Sellers EM, Giles HG, Billings BJ, Martin PR, Greenblatt DJ, Marshman JA: Interaction of disulfiram with benzodiazepines. Clin Pharmacol Ther 24:583-589, 1978

58. Skinner HA, Sheu W-J: Reliability of alcohol use indices: The Lifetime Drinking History and the MAST. J Stud Alcohol 43:1157-1170, 1982

59. Adams KM, Grant I, Carlin A, Reed R: Self-reported alcohol consumption in four clinical groups. Am J Psychiatry 138:445-449, 1979

60. American Psychiatric Association: Diagnostic and Statistical Manual of Mental Disorders, ed 4. Washington, DC, American Psychiatric Association, 1994

61. Wesson D, Carlin A, Adams KM, Beschner G: Polydrug Abuse. New York, Academic Press, 1978

62. Hutchins GD, Holden JE, Koeppe RA, Halama JR, Gatley SJ, Nickles RJ: Alternative approach to single-scan estimation of cerebral glucose metabolic rate using glucose analogs, with particular application to ischemia. J Cereb Blood Flow Metab 4:35-40, 1984

63. Mazière M, Hantraye $P$, Prenant C, Sastre J, Comar D: Synthesis of RO 1788 with ${ }^{11} \mathrm{C}$ : A specific radioligand for the in vivo study of central benzodiazepine receptors by positron emission tomography. Int J Appl Radiat Isot 35:973-976, 1984

64. Frey KA, Holthoff VA, Koeppe RA, Jewett DM, Kilbourn MR, Kuhl DE: Parametric in vivo imaging of benzodiazepine receptor distribution in human brain. Ann Neurol 30:663-672, 1991

65. Koeppe RA, Holthoff VA, Frey KA, Kilbourn MR, Kuhl DE: Compartmental analysis of $\left[{ }^{11} \mathrm{C}\right]$ flumazenil kinetics for the estimation of ligand transport rate and receptor distribution using positron emission tomography. J Cereb Blood Flow Metab 11:735-744, 1991

66. Holthoff VA, Koeppe RA, Frey KA, Paradise AH, Kuhl DE: Differentiation of radioligand delivery and binding in the brain: Validation of a two-compartment model for $\left[{ }^{11} \mathrm{C}\right]$ flumazenil. J Cereb Blood Flow Metab 11:745-752, 1991

67. Talairach J, Tournoux P: A Co-planar Stereotaxic Atlas of a Human Brain. Stuttgart, Thieme-Verlag, 1988

68. Minoshima S, Koeppe RA, Frey KA, Kuhl DE: Anatomic standardization: Linear scaling and nonlinear warping of functional brain images. J Nucl Med 35:1528-1537, 1994

69. Reitan RM, Wolfson D: The Halstead-Reitan Neuropsychological Test Battery. Tucson, Neuropsychology Press, 1986 